\title{
INTERPERSONAL TRUST IN ADOLESCENCE: A PRELIMINARY STUDY ON ONLINE/OFFLINE SOCIAL INTERACTIONS AND LIFE SATISFACTION
}

\author{
Elisa Colì \\ Institute of Cognitive Science and Technology \\ Italian National Research Council, Rome, Italy \\ elisa.coli@istc.cnr.it \\ Marinella Paciello \\ Faculty of Psychology \\ Uninettuno Telematic International University \\ Rino Falcone \\ Institute of Cognitive Science and Technology \\ Italian National Research Council, Rome, Italy \\ Giorgia Saleri \\ Faculty of Psychology \\ Uninettuno Telematic International University \\ Maria Pepe \\ Faculty of Psychology \\ Uninettuno Telematic International University \\ Arrigo Pedon \\ Faculty of Psychology \\ Uninettuno Telematic International University
}

Fecha de Recepción: 23 Julio 2019

Fecha de Admisión: 25 Septiembre 2019

\begin{abstract}
Interpersonal trust in adolescence: a preliminary study on online/offline social interactions and life satisfaction. Interpersonal trust is a key element in the development and maintenance of positive social interactions and it has been positively associated with life satisfaction (Putnam, 2000). Specifically, it is a promoting factor of physical health and psychosocial functioning during infant and adolescence (Rotenberg, 2010). In spite of the importance of trust in everyday life, there is no consensus about its definition and, in turn, about its assessment. Moreover, the role of trust in an online setting is still unknown. It may be important to explore it, since nowadays adolescents spend more and more time on the Internet, an environment where many social relationships take place. Thus, online trust could be identified as an element that can guarantee the success of these interactions (Stratford, 2000). Starting from the theoretical perspective of Falcone and Castelfranchi (2001), who defined trust as complex and dynamic construct, the present pilot study aims to inves-
\end{abstract}




\section{INTERPERSONAL TRUST IN ADOLESCENCE: A PRELIMINARY STUDY ON ONLINE/OFFLINE SOCIAL INTERACTIONS AND LIFE SATISFACTION}

tigate adolescents' online/offline trust and its influence on life satisfaction. In particular, we operationalized trust as theorized by the above-mentioned authors and based on two essential mental ingredients, which are the goals and beliefs about the trustor and trustee and the trustee's behaviour. In addition, we took into account both offline and online social interactions. The research, carried out within a middle school in the province of Naples (Italy), involved 108 adolescents, aged between 11 and 14. The data were collected through an ad hoc questionnaire. In particular, trust in online and offline interactions was measured through a 5-point Likert scale composed of 30 items; life satisfaction was investigated through the Brief Multidimensional Students' Life Satisfaction Scale (BMSLSS; Huebner et al., 2004). Factorial analysis demonstrates that online and offline trust are distinct dimensions ( $24 \%$ and $18 \%$ of explained variance respectively). In addition, only offline trust is positively related to adolescents' life satisfaction in different life domains (e.g. family, school and peer). In the overall, the results suggest the importance of distinguishing offline and online trust, and of exploring their relationships with adjustment indicators in order to understand how to promote adolescents' wellbeing.

Keywords: adolescence; interpersonal trust; online and offline social interactions; life satisfaction; online and offline trust measuring.

\section{INTRODUCTION}

Trust, trustworthy, entrust are very recurrent words in our vocabulary and trust is at the centre of our daily life. Every day we carry out endless trust actions: we rely on the doctor who takes care of us, on a website to make a purchase, on the information we find on the Web or on unknown people with whom we interact online. Trust is in all fields of an individual's associative life, both at the interpersonal relationships level, involving one or more individuals, and at the institutional relationships level, involving subjects no longer identifiable as individuals, such as trust in public and private institutions or in economic organizations (Ficorilli, 2014). Given the importance of trust in everyday life, it became the subject of several research works and has been studied by different disciplinary perspectives. Howewer, while there is an agreement on the complexity and the multidimensional nature of trust, there is no consensus about its definition (Yamagishi \& Yamagishi, 1994) and, in turn, about its assessment. This, in part, is due to the various definitions of trust we can find in literature that reflect the paradigm of the discipline of reference. For example, sociologists consider trust as a social structure, psychologists as a personality trait, economists as a rational choice mechanism (Lewicki \& Bunker, 1995). In addition, as underlined McKnight and Chervany (2000), empirical research drove most of the definitions of trust and each researcher developed a narrow conceptualization of trust that fits the type of research they conduct. In the overall, the main definitions of trust that were given can be grouped into two main strands: the first one focuses on trust as an expectation concerning the behaviour of an interaction partner (Barber, 1983; Koller, 1988), the second focuses on trust as acceptance of and exposure to vulnerability (Doney, Cannon, \& Mullen, 1998); Rosseau et al., 1998). Castelfranchi and Falcone (2010) underlined the necessity to identify a strong common conceptual kernel for characterizing the general notion of trust. Trust, as theorized by authors (Falcone \& Castelfranchi, 2001; Castelfranchi \& Falcone, 2010), is a complex mental attitude based on two essential mental ingredients, which are the goals and beliefs about the trustor and trustee and the trustee's behaviour.

With particular reference to interpersonal trust, researchers demonstrated that it is an important component of social capital (Salmi, Smolej, \& Kivivuori, 2007) and, specifically, a key element in the development and maintenance of positive social interactions (Randall et al., 2010). Furthermore, interpersonal trust was positively associated with life satisfaction (Putnam, 2000), even if some aspects of this relationship must to be still clarified. Some studies pointed out the positive conse- 
quences of high levels of interpersonal trust in social life, particularly in interacting with other people. Results of these studies showed that people with high levels of trust are less likely to lie, to cheat or steal than people with low levels of interpersonal trust; in addition, they are more likely to respect the rights of others. Moreover, these people are less likely to be unhappy, conflicted, or maladjusted, and they are more likely to have many friends (Rotter, 1980). Interpersonal trust plays a central role during infancy and adolescence. Specifically, it is a promoting factor of physical health and psychosocial functioning during these life stages (Rotenberg, 2010; Zongkui, 2008), affecting the relationships with parents and peers (Bernath \& Feshbach, 1995; Harris, 2007). Researchers measured the level of adolescents' trust, investigating the factors that can affect it. Results of these studies highlighted high levels of interpersonal trust in interviewed adolescents. Furthermore, they highlighted that there are significant differences as regards gender and urban or rural provenance, and they revealed the influence of some personality traits and of specific coping styles (Chun, 2013). Adolescents' trust was also studied in connection with loneliness and self-disclosure, pointing out that adolescents who were lonelier had lower levels of interpersonal trust than adolescents who were less Ionely (Rotenberg, 1994; Hamid \& Lok, 2000). They did not find a positive relationship between self-disclosure and trust instead (Vondracek \& Marshall, 1971).

Nowadays adolescents spend more and more time on the Internet, the environment were many of the social relationships take place. Trust plays a central role in face-to-face interactions as well as in online ones. In particular, trust was identified as an element that can guarantee the success of these interactions (Stratford, 2000), as well as the precursor of an active engagement in online environments (Hoff, 2016). As regards the definition of online trust, Beldad, De Jong and Steehouder (2010) highlighted that the classic trust definitions can be applied to trust in online relationships, therefore online trust and face-to-face trust would seem to be based on the same fundamental ingredients. As regards the studies on online trust, the main group of them was focused on online shopping, aimed at identifying factors promoting the development of online trust (Gefen, Karahanna, \& Straub, 2003; Kuan \& Bock, 2007; Koehn, 2003; Salo \& Karjaluoto, 2007) and at studying the impact that consumers' trust has on online purchase intentions (Chen \& Barnes, 2007; Ling, Chai, \& Piew, 2010). Other researchers, such as Henderson and Gilding (2004), studied trust in online communication, exploring the foundations of trust in online friendships and identifying four sources of online trust, namely reputation, performance, pre-commitment and situational factors. Bryce and Fraser (2014) analysed adolescents' online trust instead, pointing out that they had a lower level of trust in people they interacted with online, unless they were part of their existing peer network. These results contrast with the general perception of young people as naive and trusting the people they interact with online, suggesting that adolescents are aware of the risks associated with interacting with 'strangers' online.

Another less considerable group of studies was focused on online and offline trust (Mesch, 2012; Feng, Lazar, \& Preece, 2004), highlighting the presence of a relationship between the daily trust attitude and online interpersonal trust. Specifically, people who were more trusting in their daily life experienced more difficulties in developing trust online, whereas people who were less trusting in their daily life were more inclined to develop trust online. However, different results achieved in other experimental scenarios, suggest that the type of online communities and discussion topics affect the change of trust attitude between daily life and online life.

Despite the increasing dissemination of studies on online trust, the role of trust in online setting is still unknown or not sufficiently investigated, especially as regards adolescents' social interactions. Furthermore, the relationship between online and offline trust is still unclear and the results of the few studies conducted are inconsistent. In addition, this relationship was not investigated with 


\section{INTERPERSONAL TRUST IN ADOLESCENCE: A PRELIMINARY STUDY ON ONLINE/OFFLINE SOCIAL INTERACTIONS AND LIFE SATISFACTION}

reference to adolescents' social interactions. It is still unclear how mechanisms of online and offline trust operate and what are the elements, apart from physical distance, that affect them. The relationship between trust and life satisfaction remains to be clarified as well.

\section{AIMS OF THE STUDY \\ Starting from the considerations made above, the present preliminary study aims to investigate adolescents' online/offline trust and its association with life satisfaction. In particular, we opera- tionalized trust as theorized by Falcone and Castelfranchi (2001) and based on two essential mental ingredients that are goals and beliefs about the trustor and trustee and the trustee's behaviour. In addition, we took into account both online and offline adolescents' social interactions. In some way, this paper intend to contribute to the debate on online and offline trust addressing the problem of their definitions and measuring. \\ In particular, a twofold objective described below was pursued: \\ developing a new tool to assess trust in online and offline relationships; \\ presenting the relationship between online/offline trust and life satisfaction, both in general and in different contexts, such as family or school.}

\section{SAMPLE}

The sample of this study included 108 adolescents, $54 \%$ male and $46 \%$ female ones, aged between 11 and $14(M=12)$. The participants were students from a single middle school based in the South of Italy.

\section{METHODOLOGY AND INSTRUMENTS USED}

This study used an ad hoc questionnaire as main tool for data collection. The tool used was designed by combining parts of different surveys in order to better understand the multiple facets of participants' lives. The questionnaire was composed of five sections. The first part was built to acquire socio-demographic information and data relating to time and use of the Internet. Moreover, this section also deals with the issues of perceived social support and social networking. The second part was aimed at exploring the social representations through the structural approach (Abric, 2001) and the method of free associations (Verges, 1992). The third part of this questionnaire was aimed at investigating any problematic use of the Internet through the GPIUS2 (Caplan, 2010), a 16item questionnaire with an 8-point Likert response scale ( 1 = strongly disagree; 8 = strongly agree). Trust in online and offline interactions was measured in the fourth section through a 5-point Likert scale ( 1 = strongly disagree; 5 = strongly agree) composed by 32 items. The last segment was devoted to assessing life satisfaction with the aid of the Brief Multidimensional Students' Life Satisfaction Scale (BMSLSS; Huebner et al., 2004). The last two sections of the questionnaire embodied the focus of this study. The collected data were analyzed through correlation and factor analysis.

\section{ACHIEVED RESULTS}

In order to evaluate psychometric properties, the factorial structure of the interpersonal trust scale was examined through the Analysis of the Principal Components applying the oblimin rotation of the factor axes. The following elements were considered: analysis of the scree-test, the percentage of variance, explanation of the factors, the validity of the content based on the article, examination of the saturations of the articles on the extracted factors. Factor analysis revealed two factors which explain $42,48 \%$ of the variance. In Table 1 it is possible to observe that the first factor is characterized by items regarding trust in online environments while the second one is represented by 
items related to trust in face-to-face relationships. Therefore, based on the contents of the items, factor 1 was called "Online Trust Factor" (23,9\% of the variance) and factor 2 "Face-to-face Trust Factor" (18,5\% of the variance). The reliability of both dimensions of interpersonal trust is very high ("Online Factor" $\alpha=.90$; "Face to Face Factor" $\alpha=.86$ ).

Table 1. Factor Loadings for Exploratory Factor Analysis of the Interpersonal Trust Scale

\begin{tabular}{lrr}
\hline & Online Trust & Face-to-face Trust \\
& Factor & Factor \\
\hline I'm complicit with people online & $\mathbf{0 , 8 1}$ & 0,01 \\
People online are interested in my goals achieving & $\mathbf{0 , 7 9}$ & $-0,07$ \\
People online direct me towards other forms of help & $\mathbf{0 , 7 6}$ & $-0,22$ \\
People online help me in achieving goals & $\mathbf{0 , 7 4}$ & 0,04 \\
People online support me adequately & $\mathbf{0 , 7 3}$ & $-0,06$ \\
People online can support me & $\mathbf{0 , 7 3}$ & $-0,10$ \\
People online are always available & $\mathbf{0 , 7 3}$ & $-0,08$ \\
People online understand my goals & $\mathbf{0 , 6 9}$ & 0,01 \\
I have faith in people online & $\mathbf{0 , 6 9}$ & 0,03 \\
People online are attentive to requests & $\mathbf{0 , 6 8}$ & $-0,10$ \\
People online know my goals & $\mathbf{0 , 6 6}$ & 0,11 \\
People online can keep my problems to themselves & $\mathbf{0 , 6 5}$ & $-0,17$ \\
It's important that people online help me achieve my & & \\
goals & $\mathbf{0 , 6 0}$ & 0,04 \\
People online could do more in person & $\mathbf{0 , 3 6}$ & 0,16 \\
I don't ask for help to people face-to-face because I ask & & \\
for help elsewhere & $\mathbf{0 , 3 3}$ & 0,14 \\
People face-to-face help me in achieving goals & $-0,12$ & $\mathbf{0 , 7 4}$ \\
I'm complicit with people face-to-face & $-0,03$ & $\mathbf{0 , 7 3}$ \\
People face-to-face understand my goals & 0,02 & $\mathbf{0 , 7 2}$ \\
People face-to-face are always available & 0,05 & $\mathbf{0 , 6 9}$ \\
People face-to-face are interested in my goals achieving & 0,03 & $\mathbf{0 , 6 6}$ \\
People face-to-face support me adequately & $-0,26$ & $\mathbf{0 , 6 4}$ \\
People face-to-face know my goals & 0,12 & $\mathbf{0 , 6 1}$ \\
People face-to-face are attentive to requests & 0,03 \\
People face-to-face point me towards other forms of help & $-0,28$ & $\mathbf{0 , 6 0}$ \\
People face-to-face can keep my problems to themselves & $-0,09$ & $\mathbf{0 , 5 8}$ \\
People face-to-face can support me & 0,03 \\
I have faith in people face-to-face & $-0,20$ & $\mathbf{0 , 5 7}$ \\
It's important that people face-to-face help me achieve & & $\mathbf{0 , 5 6}$ \\
my goals & 0,19 & $\mathbf{0 , 5 5}$ \\
People face-to-face could do more virtually & 0,19 & $\mathbf{0 , 5 3}$ \\
I don't ask for help to people online because I ask for & & $\mathbf{0 6}$ \\
help elsewhere & 0,04 & $\mathbf{0 0}$ \\
Alpha & & $\mathbf{0 , 2 9}$ \\
\hline & &
\end{tabular}

With regard to the mean differences the adolescent's face-to-face trust is higher than online trust $[F(1,105)=99,8 ; p<0.1-$ figure 1]. Specifically, girls show higher levels of face-to-face trust than those of males (girls: mean $=3.73$; $d s=.72$; boys: mean $=3.28$; $d s=.73$ ). 


\section{INTERPERSONAL TRUST IN ADOLESCENCE: A PRELIMINARY STUDY ON ONLINE/OFFLINE SOCIAL INTERACTIONS AND LIFE SATISFACTION}

Figure 1. Mean level of face-to-face and online trust factors

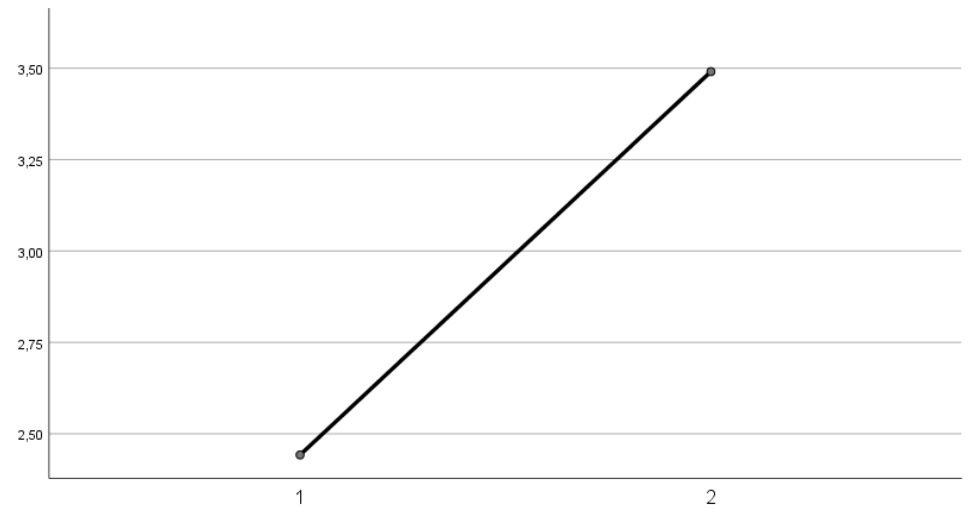

Correlation analysis shows that "Online Trust Factor" and "Face-to-face Trust Factor" represent two distinct parameters $(r=.06 ; p=.53)$. As it is possible to observe in Table 2, the correlational patterns of these two dimensions differ in terms of life satisfaction: only trust in offline relationships is positively and significantly associated with gratification in terms of family, friendships, school and self.

Table 2. Correlation between Life Satisfaction and Face-to-face/Online Trust Factors

\begin{tabular}{lrr}
\hline & \multicolumn{3}{c}{$\begin{array}{l}\text { Online } \\
\text { Face-to-face } \\
\text { Trust Factor }\end{array}$} & $\begin{array}{l}\text { Trust } \\
\text { Factor }\end{array}$ \\
\hline Satisfaction TOTAL & $\mathbf{. 2 2}$ & .06 \\
Satisfaction with family & $\mathbf{3 0}$ & -.03 \\
Satisfaction with friendship & $\mathbf{3 3}$ & .09 \\
Satisfaction with school & $\mathbf{. 3 3}$ & -.10 \\
Satisfaction with myself & $\mathbf{. 2 9}$ & .06 \\
Satisfaction with where I live & $\mathbf{. 2 0}$ & $\mathbf{. 1 9}$ \\
\hline
\end{tabular}

\section{DISCUSSION AND CONCLUSION}

First of all, with respect to the measurement of trust, the tool developed for this research showed that online trust and offline trust, even if including the same elements, are two distinct constructs that probably operate differently due to the diversity of the environments. For example, an online environment is certainly more complex than an offline one due to the mediation of several factors. Therefore, it is essential to identify the set of factors that affect the constituent components of online and offline trust, so that they can guide the development of ad hoc tools based on field of use, as for example, it was done for measuring trust between doctor and patient (Colì, Montani \& Falcone, 2019).

Furthermore, the results of our research show that adolescents have high level of face-to-face trust and low level of online trust, in line with a part of literature studies (Mesch, 2012; Feng, Lazar \& Preece, 2004). On the one hand, this would confirm a non-linear relationship between online and 
offline trust, as highlighted by literature (i.e. a high offline trust does not necessarily imply a high online trust). On the other hand, it would suggest that we are dealing with adolescents, who are aware of the risks present on the Web and of the consequences deriving from a misplaced trust. In order to deepen the meanings that adolescents attributed to trust, and to better understand the differences between the constructs of online and offline trust, it may be interesting to investigate the social representation of trust that different groups of adolescents have, for example, teenagers with high levels of online trust and teenagers with high levels of offline trust.

As regards the relationship between trust and gender, our research showed that females have greater confidence than males in face-to-face interactions, and this is in line with literature, which highlights gender differences in this regard (Chun, 2013). This gender difference disappears in online trust, and therefore in our research the PC mediation in online interactions would seem to eliminate gender differences. The relationship between trust and gender deserves further study in order to understand why males and females operate differently when they interact with others faceto-face and in the same way when they interact with others online.

As regards the relationship between trust and life satisfaction, our study pointed out that there is a positive relation between the two constructs, as well as in literature (Putnam, 2000). However, in our study this relationship emerges only in the case of offline trust, not finding a counterpart in the case of online trust. Therefore, it would seem that only putting trust in face-to-face relationships could contribute to increase life satisfaction in general, and in the different areas of one's life, in particular. Ours is the first study that aims to investigate the association between online trust and life satisfaction, a relationship that should be further investigated in future studies in order to better understand the results of this research. In particular, it would be interesting to identify the elements that contribute to mediate this relationship in the case of online social interactions; one of these could be, for example, the absence of an immediate response concerning the trust placed online.

To conclude, this research highlights the importance of analysing trust not only in direct relationships between individuals, but also and above all in relationships in virtual environments, because of the important implications that trust can have for these relationships and for related consequences in everyday life. For example, trust and the related perception of security on the Net lead individuals to share information belonging to the private sphere, assuming (at times incorrect) beliefs about their interlocutors. The uncontrolled circulation of personal data, photos and videos involves several risks that could also affect the satisfaction and quality of life of the trustors. Antinormative conducts such as cyberbullying, grooming and revenge porn are closely linked to misplaced trust that leads to the dissemination and exploitation of the shared information. Thus, by exploring trust in virtual environments it can be possible to better understand these situations and educate potential victims, often adolescents, to a more conscious use of the Web. In the light of our findings, we underline the need to identify elements that make trust relationships in online contexts different from those experienced face-to-face. A further element to be investigated should be the trustee, which could be represented both by users with whom we have exclusively online contacts and by the Internet users with whom we also have face-to-face relationships. Future studies could provide important data that may allow to deepen the construct under examination and to analyse how it is associated with life satisfaction.

\section{BIBLIOGRAPHIC REFERENCES}

Abric J.C. (2001). A structural approach to social reprèsentations. In Deaux K. and Philogène G., editors, Representations of the social: Bridging theoretical traditions. Malden: Blackwell Publishing, pp. 42-47.

Barber, B. (1983). The logic and limits of trust. New Jersey: Rutgers University Press 


\section{INTERPERSONAL TRUST IN ADOLESCENCE: A PRELIMINARY STUDY ON ONLINE/OFFLINE SOCIAL INTERACTIONS AND LIFE SATISFACTION}

Beldad, A., De Jong, M., \& Steehouder, M. (2010). How shall I trust the faceless and the intangible? A literature review on the antecedents of online trust. Computers in human behavior, 26(5), 857869.

Bernath, M. S., \& Feshbach, N. D. (1995). Children's trust: Theory, assessment, development, and research directions. Applied and Preventive Psychology, 4(1), 1-19.

Bryce, J., \& Fraser, J. (2014). The role of disclosure of personal information in the evaluation of risk and trust in young peoples' online interactions. Computers in Human Behavior, 30, 299-306.

Caplan, S. E. (2010). Theory and measurement of generalized problematic Internet use: A two-step approach. Computers in Human Behavior, 25, 1089-1097

Castelfranchi, C., \& Falcone, R. (2010). Trust theory: A socio-cognitive and computational model (Vol. 18). John Wiley \& Sons.

Chen, Y. H., \& Barnes, S. (2007). Initial trust and online buyer behaviour. Industrial management \& data systems, 107(1), 21-36.

Chun, Y. A. 0. (2013). College Students' Interpersonal Trust Status and Influential Factors. Journal of Langfang Teachers College (Natural Science Edition), 2013-05.

Colì, E., Montani, F., \& Falcone, R. (2019). La relazione medico-paziente nell'era del Web 2.0: una ricerca esplorativa su rappresentazioni sociali, mediazione di internet e fiducia. Psicologia della Salute, 2/2019, 28-52.

Doney, P. M., Cannon, J. P., \& Mullen, M. R. (1998). Understanding the influence of national culture on the development of trust. Academy of Management Review, 23(3), 601-620.

Falcone, R., \& Castelfranchi, C. (2001). Social Trust: A Cognitive Approach, in Trust and Deception in Virtual Societies by Castelfranchi C. and Yao-Hua Tan (eds), Kluwer Academic Publishers, pp. 55-90.

Feng, J., Lazar, J., \& Preece, J. (2004). Empathy and online interpersonal trust: A fragile relationship. Behaviour \& Information Technology, 23(2), 97-106.

Ficorilli, A. (2014). La relazione di fiducia: un approccio bioetico alle questioni della cura. Firenze: Le Lettere.

Gefen, D., Karahanna, E., \& Straub, D. W. (2003). Trust and TAM in online shopping: an integrated model. MIS Quarterly, 27(1), 51-90.

Hamid, P. N., \& Lok, D. P. (2000). Loneliness in Chinese adolescents: a comparison of social support and interpersonal trust in 13 to 19 year olds. International Journal of Adolescence and Youth, 8(1), 45-63.

Harris, P. L. (2007). Trust. Developmental Science, 10, 135-138

Henderson, S., \& Gilding, M. (2004). 'I've never clicked this much with anyone in my life': trust and hyperpersonal communication in online friendships. New media \& Society, 6(4), 487-506.

Hoff, M. J. (2016). "I don't conversate with those I don't know": The role of trust/distrust in online engagement. Digital Culture \& Education, 8(2).

Huebner, E. S., Suldo, S., Valois, R. F., Drane, J. W., \& Zullig, K. (2004). Brief multidimensional students' life satisfaction scale: sex, race, and grade effects for a high school sample. Psychological Reports, 94(1), 351-356.

Koehn, D. (2003). The nature of and conditions for online trust. Journal of Business Ethics, 43(1-2), 3-19.

Koller, M. (1988). Risk as a determinant of trust. Basic and Applied Social Psychology, 9(4), 265276.

Kuan, H. H., \& Bock, G. W. (2007). Trust transference in brick and click retailers: An investigation of the before-online-visit phase. Information \& Management, 44(2), 175-187. 
Lewicki, R. J., \& Bunker, B. B. (1995). Trust in relationships: A Model of Trust Development and Decline. Administrative Science Quarterly, 5(1), 583-601.

Ling, K. C., Chai, L. T., \& Piew, T. H. (2010). The effects of shopping orientations, online trust and prior online purchase experience toward customers' online purchase intention. International Business Research, 3(3), 63.

McKnight, D. H., \& Chervany, N. L. (2000). What is trust? A conceptual analysis and an interdisciplinary model. AMCIS 2000 Proceedings, 382.

Mesch, G. S. (2012). Is online trust and trust in social institutions associated with online disclosure of identifiable information online? Computers in Human Behavior, 28(4), 1471-1477.

Putnam, R. D. (2000). Bowling alone: The collapse and revival of American community. New York: Simon and Schuster.

Randall, B. A., Rotenberg, K. J., Totenhagen, C. J., Rock, M., \& Harmon, C. (2010). A new scale for the assessment of adolescents' trust beliefs. Interpersonal trust during childhood and Adolescence, 247.

Rotenberg, K. J. (Ed.). (2010). Interpersonal trust during childhood and adolescence. Cambridge University Press.

Rotenberg, K. J. (1994). Loneliness and interpersonal trust. Journal of Social and Clinical Psychology, 13(2), 152-173.

Rotter, J. B. (1980). Interpersonal trust, trustworthiness, and gullibility. American Psychologist, 35(1), 1-7.

Rousseau, D. M., Sitkin, S. B., Burt, R. S., \& Camerer, C. (1998). Not so different after all: A crossdiscipline view of trust. Academy of Management Review, 23(3), 393-404.

Salmi, V., Smolej, M., \& Kivivuori, J. (2007). Crime victimization, exposure to crime news and social trust among adolescents. Young, 15(3), 255-272.

Salo, J., \& Karjaluoto, H. (2007). A conceptual model of trust in the online environment. Online Information Review, 31(5), 604-621.

Stratford, T. (1999). Etrust: building trust online. Journal on Integrated Communications, 10, 75-81.

Verges P. (1992). L'évocation de l'argent: une méthode pour la définition du noyau central d'une représentation. Bulletin de Psychologie, 45 (405): 203-209.

Vondracek, F. W., \& Marshall, M. J. (1971). Self-disclosure and interpersonal trust: An exploratory study. Psychological Reports, 28(1), 235-240.

Yamagishi, T., \& Yamagishi, M. (1994). Trust and commitment in the United States and Japan. Motivation and Emotion, 18(2), 129-166.

Zongkui, K. F. Z. (2008). Survey on Factors Affecting Development of Adolescent Interpersonal Trust. Science of Social Psychology, Z1. 
